\title{
IDENTITAS SEORANG KATEKIS PROFESIONAL DEWASA INI
}

\author{
Oleh: \\ Albert I Ketut Deni Wijaya \\ STKIP WidyaYuwana
}

\begin{abstract}
The work of catechesis as a work of developing faith in Christ, of course requires a diverse range of catechists. The types of catechists can be distinguished by time to work, education, and various catechetical needs. This paper aims to explain the identity of a catechist. The discussion of catechist identity includes catechism, catechist spirituality, catechism in the mission of the Church and professional climate, the Holy Spirit in the mission of catechists.Catechists are required to continually develop themselves. The development covers aspects of spirituality, knowledge and skills.
\end{abstract}

Keywords: identity, catechesis, professional catechist

\section{PENDAHULUAN}

Pewartaan Injil merupakan tugas utama Gereja, bahkan merupakan jati diri Gereja. Dalam menjalankan karya pewartaannya Gereja memanggil setiap anggotanya menjadi pewarta dan saksi tentang Yesus Kristus dan Injil-Nya sesuai dengan kemampuan dan kedudukan mereka masing-masing (Adisusanto, 1993: 66). Panggilan ini menurut Pedoman untuk Katekis (Komkat KWI, 1997: 15) bersumber dari Roh Kudus. Kelompok awam yang secara khusus menanggapi panggilan tersebut adalah katekis. Ad Gentes artikel 17 menyebut katekis sebagai salah satu jajaran pekerja karya misioner yang mempunyai peran sangat penting dalam perjalanan sekuler pewartaan Injil. Selain itu, katekis dinilai sebagai para pewarta yang tidak tergantikan (Komkat KWI, 1997: 7)

Banyak permasalahan seputar istilah katekis. Tulisan ini bertujuan menjelaskan tentang jati diri seorang katekis. Pembahasan tentang identitas katekis meliputi pengertian katekis, spiritualitas katekis, katekis dalam perutusan Gereja dan iklim profesional serta peran serta Roh Kudus dalam perutusan katekis.

\section{PENGERTIAN KATEKIS}

Terdapat beraneka pemahaman tentang katekis yang berkembang dalam masyarakat Gereja. Kotan (2005: 145-147) menyampaikan aneka pandangan tentang katekis. Pertama, katekis dipahami sebagai orang yang bekerja di bidang pewartaan, entah purna waktu ataupun paruh waktu serta entah apapun latar belakang keahliannya. Katekis adalah mereka yang menjalankan tugas 
pendampingan iman, mempersiapkan penerima sakramen-sakramen, memimpin/memandu katekese umat, dan lain sebagainya. Kedua pandangan yang menempatkan katekis sebagai kaum awam yang terlibat dalam karya pastoral Gereja, seperti pendampingan kaum muda, pendampingan kaum buruh bahkan pemimpin ibadat. Ketiga, katekis dipahami sebagai orang yang memiliki pendidikan formal sebagai katekis, atau memiliki ijazah Pendidikan Tinggi Kateketik.

\subsection{Identitas Katekis}

Setiap orang beriman termasuk kaum awam mendapat hak serta kewajiban untuk ambil bagian dalam karya keselamatan Allah bagi semua orang, karena sakramen permandian dan dikuatkan oleh Roh Kudus dalam sakramen penguatan, (Mandagi, 1994: 11). Pedoman untuk Katekis (Komkat KWI, 1997: 15) melihat katekis sebagai anggota kaum awam yang dipanggil secara khusus oleh Roh Kudus, di mana oleh Gereja diakui sebagai 'karisma khusus' dan diperjelas melalui tugas perutusan dari Uskup.

Banyak dokumen mengungkapkan pandangannya tentang katekis. Kitab Hukum Kanonik kanon 785 menyebut katekis sebagai umat kristiani awam yang dididik terutama dalam kehidupan kristiani di bawah bimbingan seorang misionaris, memiliki tugas dalam karya pewartaan injil, perayaan-perayaan liturgi, serta cinta kasih.

"Umat beriman kristiani awam yang sungguh-sungguh dibina dan yang unggul dalam kehidupan kristiani; mereka itu di bawah bimbingan seorang misionaris, mencurahkan tenaganya dalam pewartaan ajaran injil dan dalam perayaan-perayaan liturgi serta karya amal kasih.” (KHKkanon 785)

Ad Gentes artikel 17 menyebut katekis sebagai barisan dalam karya misioner di antara para bangsa, di mana mereka dijiwai oleh semangat merasul dan memberikan banyak bantuan demi karya perluasan iman dan Gereja.

"Demikian pula pantas dipujilah barisan, yang berjasa begitu besar dalam karya misioner di antara para bangsa, yakni barisan para katekis baik pria maupun wanita, yang dijiwai semangat merasul, dengan jerih payah memberi bantuan yang istimewa dan sungguh-sungguh perlu demi penyebarluasan iman dan Gereja. (AG 17)”

Redemptoris Missio artikel 73 mengulang kembali pengertian katekis berdasarkan Ad Gentes artikel 17. Redemptoris Missio selanjutnya menambahkan bahwa istilah 'katekis' terutama dikenakan kepada para pewarta di tanah-tanah misi, sebab Gereja-gereja yang dewasa ini sedang mekar kiranya tidak mungkin telah dibangun tanpa mereka itu. Pedoman untuk Katekis (Komkat KWI, 1997: 17) 
menyebut katekis sebagai "seorang awam yang ditunjuk secara khusus oleh Gereja, sesuai dengan kebutuhan setempat, untuk memperkenalkan Kristus, dicintai dan diikuti oleh mereka yang belum mengenal-Nya dan oleh kaum beriman itu sendiri”. Pedoman untuk Katekis (Komkat KWI, 1997: 17) melanjutkan bahwa: "Dalam kegiatannya yang biasa, katekis bukan sekedar pengganti imam, melainkan menurut hukum adalah seorang saksi Kristus dalam komunitas tersebut”. Kotan (2005: 133) juga menulis identitas katekis:

"Katekis adalah orang beriman yang dipanggil secara khusus dan diutus Allah serta mendapat penugasan dari Gereja melalui missio canonica dari Gereja terutama dalam karya pewartaan Gereja untuk memperkenalkan, menumbuhkan dan mengembangkan iman umat, ... Dalam tugas pewartaan itu mereka berperan sebagai: penafsir, pewarta, pendamping, penggerak, fasilitator, pemberdaya yang profesional.”

Berdasarkan berbagai pendapat di atas, bias disimpulkan bahwa katekis adalah seorang beriman kristiani, telah menerima baptis, penguatan dan ekaristi serta termasuk kelompok awam; Katekis secara khusus menanggapi panggilan Roh Kudus untuk menjadi pewarta; belajar secara khusus tentang hidup kristiani dan mendalaminya dalam seluruh kehidupannya; mendapat tugas perutusan resmi dari Gereja (missio canonica); memiliki semangat merasul dalam membaktikan dirinya bagi karya pewartaan injil serta saksi Kristus bagi semua manusia.

\subsection{Jenis Katekis}

Penyelenggaraan katekese oleh Gereja selalu dipandang sebagai salah satu tugasnya yang amat penting. Hal ini berdasarkan perintah yang disampaikan Yesus sebelum Ia naik ke surga untuk menjadikan semua bangsa murid-Nya (CT 1). Karya katekese sebagai karya mengembangkan iman akan Kristus, tentunya memerlukan tenaga katekis yang beraneka ragam. Jenis-jenis katekis dapat dibedakan berdasarkan waktu untuk berkarya, pendidikan, dan aneka kebutuhan katekese.

Pedoman untuk Katekis (Komkat KWI, 1997: 17) membedakan dua tipe utama katekis, yaitu: katekis purna waktu (full time) dan katekis paruh waktu (part time). Katekis purna waktu (full time) adalah katekis yang mengabdikan seluruh hidupnya demi pelayanan ketekese dan diakui secara resmi sebagai katekis. Katekis paruh waktu (part time) adalah katekis yang membaktikan dirinya kepada karya katekese secara terbatas namun disertai rasa tulus dan serius atau katekis yang tidak secara penuh membaktikan hidupnya sebagai katekis. Selain dua jenis tersebut, Kotan (2005: 143) menambahkan dua jenis lagi yaitu: katekis kontrak dan katekis sukarelawan. Katekis kontrak adalah katekis yang dikontrak untuk jangka waktu tertentu. Katekis sukarelawan adalah katekis yang 
merelakan dirinya untuk menjadi tenaga katekese tanpa batas waktu dan tanpa meminta upah. Sebagai sukarelawan ketekis bekerja berdasarkan niat baiknya sendiri dan diakomodir oleh lembaga terkait, serta berprinsip ikut serta dalam karya pewartaan Injil.

Katekis juga bias dibedakan menurut pendidikannya. Ada katekis akademis dan non akademis. Katekis akademis adalah katekis yang memiliki dasar pendidikan formal di suatu lembaga pendidikan khusus, seperti lembaga Kateketik, Pastoral, Filsafat atau Teologi. Berdasarkan jenjang akademis, katekis dibagi menjadi katekis berijazah Diploma II (D-2), Diploma III (D-3), Strata 1 (S-1) dan Strata 2 Teologi (S-2). Katekis non akademis adalah katekis yang tidak memiliki dasar pendidikan formal kateketik, pastoral, filsafat ataupun teologi, namun mereka memiliki sertifikat yang diperoleh setelah mengikuti kursus atau pelatihan menjadi katekis (Kotan, 2005: 143-144).

Katekis juga dapat dibedakan menjadi katekis di negeri misi, katekis bagi kaum muda dan orang dewasa, katekis bagi anak-anak dan kaum remaja, katekis untuk pertemuan prasakramental, dan katekis-katekis lain bagi situasi yang berbahaya. Catechesi Tradendae artikel 66 menjelaskan katekis di negeri misi sebagai katekis yang lahir dari keluarga yang sudah kristen atau suatu ketika masuk agama kristen, menerima pendidikan dari para misionaris atau dari seorang katekis kemudian membaktikan hidupnya dari tahun ke tahun kepada katekese bagi anak-anak dan orang dewasa di negeri mereka (daerah misi).

Petunjuk Umum Katekese 232mengatakan bahwa katekis bagi kaum muda dan orang dewasa adalah mereka yang berada di negara-negara bertradisi kristiani yang menuntut suatu "evangelisasi baru” guna melanjutkan karya ketekese yang sudah diterimanya. Petunjuk Umum Katekese 232juga memandang perlunya katekis bagi anak-anak dan kaum remaja, sebab mereka bertugas memberikan pengertian tentang katekismus dan persiapan menerima sakramen tobat, komuni pertama dan penguatan. Katekis untuk pertemuan prasakramental adalah katekis yang diperuntukkan bagi orang dewasa untuk kesempatan permandian dan komuni pertama dari anak-anaknya atau perayaan perkawinan. Petunjuk Umum Katekese 232 memandang perlunya katekis-katekis lain dalam situasi yang berbahaya. Katekis-katekis yang dimaksud meliputi katekis yang diperuntukkan bagi mereka yang lanjut usia, membutuhkan suatu penyajian Injil yang disesuaikan dengan keadaan; katekis bagi penyandang cacat yang membutuhkan pedagogi khusus sebagai tambahan bagi pengintegrasian mereka dalam komunitas; katekis bagi kaum migran dan mereka yang tersisihkan oleh perkembangan masyarakat modern. 


\section{SPIRITUALITAS KATEKIS}

Spiritualitas bagi katekis merupakan hal yang sangat penting, sebab bersumber dari panggilan dan tugas perutusan mereka. Tondowidjojo (1990: 6970) dan Pedoman untuk Katekis (Komkat KWI, 1997: 22-23) menyampaikan bahwa spiritualitas katekis mencakup suatu motivasi baru dan khusus, suatu panggilan kepada kesucian hidup.Spiritualitas katekis juga memiliki kaitan erat dengan status mereka sebagai kaum awam Kristiani yang berperan serta sesuai tingkatannya dalam karya kenabian, imamat dan rajawi Kristus. Hakekat dari spiritualitas katekis adalah bahwa mereka sebagai anggota Gereja kelompok kaum awam yang berada di tengah-tengah dunia sekuler, mempunyai kewajiban khusus untuk meresapi hal-hal duniawi dengan semangat Injil.

Tondowidjojo (1990: 69-70) juga menyampaikan bahwa katekis yang termasuk kaum awam berkat permandian menjadi orang yang sungguh-sungguh dikuduskan oleh Allah. Katekis sekaligus menjadi bagian dari umat Allah dalam perjalanan menuju Yerusalem surgawi (Ef 2:19). Katekis menjadi bagian umat Allah yang sedang berziarah menuju tanah terjanji. Para katekis kemudian mewujudkan tugas yang diembannya di dunia dengan membaharui dunia di dalam Kristus, sebab Kristus yang sengsara dan wafat di salib menjadi tanda cinta kasih Allah kepada manusia dan dunia.

Ada empat spiritualitas yang harus dimiliki seorang katekis menurut Pedoman untuk Katekis (Komkat KWI, 1997: 23-30). Empat spiritualitas tersebut meliputi terbuka terhadap sabda Tuhan, keutuhan dan keaslian hidup, semangat misioner dan devosi kepada Bunda Maria.

\subsection{Terbuka terhadap Sabda Tuhan}

Pada dasarnya tugas katekis adalah menyampaikan sabda Tuhan. Agar dapat menyampaikan sabda Tuhan Dei Verbum artikel 25 mengatakan:

"Oleh sebab itu semua rohaniwan, terutama para imam Kristus serta lain-lainnya, yang sebagai diakon atau katekis secara sah menunaikan pelayanan sabda, perlu berpegang teguh pada Alkitab dengan membacanya dengan asyik dan mempelajarinya dengan seksama.”

Sikap rohani yang paling mendasar dari seorang katekis adalah terbuka terhadap sabda yang diwartakan oleh Gereja, dirayakan dalam liturgi, dan dihayati dalam kehidupan para santo. Seorang katekis juga harus terbuka terhadap Tuhan, Gereja dan dunia (Komkat KWI, 1997: 23).

Pedoman untuk Katekis (Komkat KWI, 1997: 23-24) menuliskan bahwa keterbukaan terhadap Allah Tritunggal berarti seorang katekis mau menerima dengan penuh Allah Tritunggal untuk berdiam dan tinggal di dalam dirinya. Dengan demikian Allah yang tinggal dalam dirinya akan memberikan makna 
dalam setiap kehidupan yang dijalaninya. Dengan kata lain, seorang katekis hendaknya membiarkan dirinya ditarik dalam lingkungan Trinitas, yaitu Bapa yang menyampaikan sabda; Putra sebagai penjelmaan sabda (Yoh 8: 26; Yoh 12: 49). Akhirnya Roh Kudus menerangi pikiran, sehingga dapat membantu memahami sabda Tuhan dan mambuka hati untuk menerima sabda dengan cinta serta mempraktekkannya(Yoh 16: 12-14).Dengan demikian, spiritualitas katekis hendaknya berakar dalam sabda Tuhan yang hidup dalam dimensi Tritunggal.

Spiritualitas katekis juga membutuhkan sikap batin yang sepadan. Pedoman untuk Katekis (Komkat KWI, 1997: 24) mengungkapkan sikap sepadan dalam membagi kasih dengan Bapa yang mengharapkan setiap orang mengenal kebenaran dan diselamatkan (I Tim 2: 3-4).Sepadan dengan mencari persekutuan Kristus untuk ambil bagian dalam pikiran, pengalaman, kehadiran dan penghiburan-Nya. Sepadan dalam membiarkan Roh Kudus membentuk dirinya untuk menjadi saksi Kristus yang berani dan pewarta yang cemerlang (RM 87).

Pedoman untuk Katekis (Komkat KWI, 1997: 24-25) menyampaikan bahwa keterbukaan terhadap Gereja bagi seorang katekis memiliki arti yang mendalam. Seorang katekis memperolah amanat untuk menjadi katekis dan mewartakan sabda Tuhan secara khusus. Segala sesuatu yang dilakukan katekis tidak dapat terlepas dari Gereja. Gereja membutuhkan para katekis yang memiliki rasa tanggung jawab yang mendalam.

Pedoman untuk Katekis (Komkat KWI, 1997: 25-26) menuliskan bahwa katekis yang memiliki keterbukaan terhadap dunia dituntut peka terhadap kebutuhan dunia, karena mereka dipanggil dari tengah-tengah dunia untuk bekerja di dunia dan untuk dunia tanpa sepenuhnya menjadi milik dunia. Katekis harus sepenuhnya terlibat dalam kehidupan masyarakat di sekitar mereka, memiliki pandangan adikodrati akan kehidupan dan percaya pada sabda Tuhan yang pasti akan membuahkan hasil(Yes 55: 11).Keterbukaan terhadap dunia merupakan ciri spiritualitas katekis atas dasar cinta rasuli Kristus Gembala yang baik yang datang untuk "mengumpukan dan mempersatukan anak-anak Allah yang tercerai-berai" (Yoh 11: 52).

\subsection{Keutuhan dan Keaslian Hidup}

Sabda Allah yang ditulis dalam Kitab Suci adalah cara Allah berbicara yang dituangkan dalam tulisan di bawah hembusan Roh Kudus (PUK 96), Sabda Allah yang terkandung dalam Kitab Suci dan tradisi suci menurut Petunjuk Umum Katekese artikel 95 hendaknya: pertama, direnungkan dan dimengerti dengan lebih mendalam melalui perasaan iman seluruh jemaat di bawah bimbingan mengajar Magisterium yang mengajar dengan berwibawa; kedua dirayakan dalam liturgi, di mana sabda Allah terus-menerus dimaklumkan, didengarkan, dibatinkan dan dijelaskan; ketiga bersinar dalam kehidupan Gereja 
teristimewa melalui kesaksian kristiani dan secara khusus dari para Kudus; keempat diperdalam melalui riset teologi yang semakin membantu kaum beriman berkembang dalam pengertian akan misteri-misteri iman; dan kelima dinyatakan dalam nilai-nilai moral dan religius yang asli. Melalui cara demikian katekis dapat semakin mengenal, mengalami dan bergaul erat dengan Sabda Allah. Selain itu katekis dapat semakin mengenal Kristus, "Sebab tidak mengenal Alkitab berarti tidak mengenal Kristus” (DV 25). Selanjutnya, seluruh pengalaman hidup seharihari yang disaksikan oleh katekis dapat diteruskan melalui pewartaan.

Kitab Suci Perjanjian Baru dalam I Yohanes 1: 1-4 menuliskan bagaimana seorang pewarta sabda Tuhan harus mengawali pewartaan dari dirinya sendiri sebelum ia menjadi pewarta bagi orang lain. Pewartaan bagi diri sendiri terungkap melalui kesaksian hidup. Kesaksian hidup yang dimaksud tidak hanya dalam katakata saja, namun juga dalam seluruh tindakan konkret sehari-hari. Melalui kesaksian tersebut pewarta sabda menjadi pembawa damai dan kebahagiaan bagi orang-orang yang ada di sekitarnya dalam persekutuan dengan Allah Bapa dan Yesus Kristus.

Setiap karya pewartaan yang dilakukan harus melibatkan seluruh hidupnya. Yesus sendiri berkat Roh Kudus yang diterimanya dalam pembaptisan mendorong-Nya bersaksi dengan sungguh-sungguh. Kesaksian Yesus tidak hanya dalam kata-kata namun juga perbuatan, di mana keduanya saling mendukung dan senantiasa dihidupi sebagai kesaksian-Nya yang utama. Demikian pula katekis hendaknya meneladan Yesus, di mana kata dan perbuatan harus saling mendukung dan selalui dihidupi sebagai wujud kesaksiannya yang utama. Perlu ditegaskan kembali bahwa sabda yang katekis wartakan kepada umat hendaknya terlebih dahulu dihayati dan dipahami. Dengan menghayati dan memahami sabda, katekis dapat berbicara tentang Tuhan yang mereka kenal secara akrab seperti telah mereka lihat. Katekis juga tidak hanya mengajarkan ilmu-ilmu kemanusiaan dan pendapat pribadi, melainkan iman Gereja yang sama di seluruh dunia (Komkat KWI, 1997: 26).

Pedoman untuk Katekis (Komkat KWI, 1997: 26) mengatakan agar semua dapat tercipta, perlu katekis yang memiliki keutuhan dan keaslian hidup. Maksudnya dengan memiliki keutuhan dan keaslian hidup, katekis tidak hanya menjadi pengajar iman namun saksi iman dalam tindakan atau perbuatan nyata. Keaslian hidup yang dimaksud dari seorang katekis meliputi hidup doa, pengalaman akan Tuhan dan kesetiaan terhadap tindakan Roh Kudus.

\subsection{Semangat Misioner}

Katekis harus sadar bahwa mereka diutus untuk mengumpulkan dombadomba yang tersesat dan mewartakan Injil. 
“Ada lagi pada-Ku domba-domba lain, yang bukan dari kandang ini; domba-domba itu harus Kutuntun juga dan mereka akan mendengarkan suara-Ku dan mereka akan menjadi satu kawanan dengan satu gembala” (Yoh 10: 16).

Katekis memerlukan semangat kerasulan yang tinggi. Dengan semangat kerasulan yang tinggi, katekis akan semakin berani dan tidak malu mewartakan Injil. Para katekis semakin berusaha menjadi seorang gembala yang baik, yang mencari dombanya yang hilang sampai ditemukan kembali. Selain itu, katekis juga perlu ingat akan apa yang disampaikan santo Paulus “Celakalah aku, jika aku tidak mewartakan Injil” (I Kor 9: 16). Kata-kata ini hendaknya menjadi ilham dalam mengobarkan semangat mereka, di mana menjadi pewarta Sabda Allah harus berani dan selalu bekerja giat demi perkembangan Gereja (Komkat KWI, 1997: 27-28).

Katekis juga perlu mengingat salib sebagai lambang kemurnian perutusannya. Salib mengingatkan katekis bahwa yang mereka wartakan adalah Kristus yang disalibkan yang kemudian wafat dan bangkit pada hari ketiga. Katekis perlu mempersiapkan diri secara sungguh dalam menghadapi berbagai tantangan dan cobaan yang akan hadir dalam perutusan mereka serta memiliki daya juang yang tinggi (Komkat KWI, 1997: 28-29).

\subsection{Devosi kepada Bunda Maria}

Catechesi Tradendae artikel 73 menyebut Bunda Maria sebagai katekismus hidup, ibu dan model katekis. Melalui panggilannya, Maria telah melihat Yesus bertambah besar dalam hikmat dan rahmat (Luk 2: 52). Maria jugalah yang mengajarkan kepada Yesus pengetahuan Kitab Suci dan rencana kasih Allah kepada umat-Nya, dan juga cinta yang mendalam kepada Bapa.

"Ketika Ia dipangku olehnya, dan kemudian mendengarkannya selama hidupnya yang tersembunyi di Nazareth, Putra itu, "Putra Tunggal Bapa”, "penuh kasih karunia dan kebenaran”, dididik oleh Maria dalam pengetahuan manusiawi tentang Kitab Suci dan tentang Rencana Allah mengenai umat-Nya, dan dalam sembah sujud kepada Bapa” (CT 73)

Redemptoris Missio artikel 92 melihat Maria sebagai tokoh penting bagi para Rasul dan Gereja. Bersama para Rasul setelah kenaikan Yesus, Maria berdoa di ruangan atas (Kis 1: 14) dengan maksud memohon datangnya Roh Kudus agar memperoleh kekuatan serta keberanian melaksanakan tugas perutusan. Bagi Gereja Maria adalah teladan, ibunda sekaligus model bagi Gereja, Maria juga menjadi model cinta ke-ibunda-an yang hendaknya mengilhami semua orang yang 
bekerja sama dalam tugas perutusan apostolik Gereja, demi kelahiran kembali umat manusia.

Maria juga tidak pernah meninggalkan katekis, terutama dalam mewartakan kabar gembira kepada segala makhluk. Katekis perlu yakin bahwa karya pewartaan Injil Yesus Kristus tidak pernah boleh dipisahkan dari Bunda Maria. Gerakan perutusan Gereja untuk mewartakan Injil Yesus Kristus hanya akan memperoleh hasil yang berlimpah dan berarti bila disertai bantuan doa dan hati yang mencintai dari Perawan Maria, Bunda Gereja. Maria akan selalu membantu Gereja dengan doa dan cinta agar mampu menjadi saksi Kristus yang baik dan memperoleh buah berlimpah dalam perutusan (Martasudjita, 2005: 99100)

Maria Bunda Tuhan senantiasa memperkaya spiritualitas katekis. Berkat Maria, para katekis dapat menemukan suatu model yang sederhana dan efektif bagi dirinya sendiri dan orang lain. Model yang membantu dalam menjalankan karya perutusan yang diemban dari Yesus demi perkembangan Gereja (Komkat KWI, 1997: 29-30). Seorang katekis hendaknya seorang beriman yang merasa dirinya dipanggil Tuhan menjadi pewarta-Nya. Panggilan Tuhan tersebut sudah selayaknya dihayati dengan penuh kegembiraan bahkan menjadi sumber kegembiraan itu sendiri (Kotan, 2005: 152).

\section{Katekis dalam Perutusan Gereja dan Iklim Profesionalitas}

Dokumen-dokumen Gereja melihat peran katekis dalam perutusan Gereja sungguh sangat penting (Wijaya, 2018:8). Katekis dipandang sebagai seorang misionaris. Bahkan seorang katekis adalah santo (RM 90). Dokumen Ad Gentes artikel 17 memberi penghargaan atas kehadiran para katekis, sebab kehadiran mereka baik pria maupun wanita yang dijiwai semangat merasul telah memberikan banyak bantuan yang istimewa dan sungguh-sungguh penting bagi penyebarluasan iman dan Gereja. Kitab Hukum Kanonik kanon 785 (1) juga mengakui akan tugas dan kualitas katekis dalam karya perutusan.

Paus Yohanes Paulus II dalam beberapa dokumennya mengingatkan kembali pentingnya peran para katekis. Atas nama Gereja, Paus Yohanes Paulus II berterima kasih kepada para katekis yang telah membaktikan diri bagi pendidikan keagamaan yang terwujud dalam kegiatan sederhana dan tersembunyi namun dijalankan dengan semangat berkobar dan murah hati (CT 66). Katekis juga merupakan kaum awam yang menjadi penginjil. Katekis adalah "kaum spesialis, orang yang memberikan kesaksian langsung dari para penginjil yang tiada tergantikan” (RM 73).

Katekis dalam tugas perutusannya tetap perlu memperhatikan profesionalisme kerja. Hal ini sangat penting untuk diperhatikan, mengingat karya yang dilakukannya berdampak pada karya Gereja. (Wijaya, 2018:12-15). 
Profesionalisme kerja seorang katekis sangat bergantung pada 3 hal, yaitu spiritualitas, pengetahuan dan keterampilan. Katekis professional perlu disiapkan melalui pembinaan yang baik dan tepat. Hal ini supaya katekis mampu meneruskan Injil kepada mereka yang rindu menyerahkan diri kepada Yesus Kristus. Tujuan dari pembinaan katekis hendaknya "Membuat para katekis memiliki keterampilan dan kemampuan mengkomunikasikan pesan Injil” (PUK 235).

\section{ROH KUDUS DALAM PERUTUSAN KATEKIS}

Roh Kudus menurut Ad Gentes adalah sumber perutusan Gereja dan pribadi utama dalam seluruh perutusan Gereja (AG1). Roh Kudus menghantar Gereja ke jalan-jalan perutusan, menjabarkan perutusan Yesus Kristus yang diutus untuk mewartakan Kabar Gembira kepada kaum miskin. Roh Kudus pula yang memungkinkan karya keselamatan Allah dalam Kristus dapat sampai kepada manusia.

Karya perutusan tidak mungkin tanpa Roh Kudus. Roh Kudus adalah jiwa Gereja. Roh Kudus menerangkan kepada kaum beriman makna terdalam ajaran Yesus dan misteri-Nya. Roh Kudus harus menjadi jiwa para katekis yang merupakan para pekerja misioner sekaligus pewarta Injil. Syarat utama dan mutlak perlu agar berhasil dalam pewartaan ialah membuka diri bagi Roh Kudus dan merindukan kedatangan-Nya.

Roh Kudus bagi hidup katekis berperan sangat penting. Katekis sebagai bagian dari tugas perutusan Gereja hendaknya menjadikan Roh Kudus sebagai jiwanya. Roh Kudus bagi para katekis membawa dampak yang begitu besar. Pertama, melalui Roh Kudus katekis disadarkan bahwa karya perutusan yang dilakukan merupakan karya Tuhan. Kedua, Roh Kudus menjadi daya kekuatan yang utama bagi para katekis dalam menjalankan tugas perutusan. Ketiga, Roh Kudus menjadi penuntun para katekis pada jalan kebenaran. Keempat, Roh Kudus memberikan petunjuk bagi para katekis akan tugas perutusan yang dijalankan (Wijaya, 2016: 56-65).

Roh Kudus menyadarkan katekis bahwa karya perutusan merupakan karya Tuhan. Karya perutusan adalah karya Tuhan, Tuhan sendirilah yang merencanakannya. Tanpa Roh Kudus, katekis akan mengalami kesulitan untuk menerima rencana dan kehendak Tuhan; katekis dalam berkarya akan bertindak atas kehendak sendiri dan bukan kehendak Tuhan. Roh Kudus memanggil para katekis sekaligus menjadi daya kekuatan utama bagi para katekis. Katekis sebagai para pekerja misioner, dipanggil Roh Kudus untuk menjadi para pewarta sabda Allah. Tanpa panggilan dari Roh Kudus tidak ada katekis yang bersedia berkarya sebagai pewarta sabda Allah. 
Roh Kudus menyiapkan jiwa para pendengar untuk terbuka dan siap menerima Injil yang sedang diwartakan. Katekis harus sadar bahwa Roh Kudus menjadi pemeran utama dalam tugasnya sebagai seorang pewarta dan tidak ada kekuatan lain yang dapat menggantikan peran Roh Kudus dalam karya pewartaan Injil, sebab Roh Kudus tiada hentinya menyertai dan memimpin dengan pelbagai cara karya pewartaan Injil.

Katekis yang menyadari panggilannya oleh Roh Kudus hendaknya senantiasa mengusahakan hidup yang sesuai dalam Roh. Usaha yang hendaknya dilakukan adalah: rajin membaca Kitab Suci; senantiasa mendekatkan diri kepada Tuhan melalui doa dan memohon berkat Tuhan supaya mengaruniakan Roh Kudus-Nya agar memberi kekuatan; doa yang semakin memuncak dalam perayaan ekaristi; menghayati panggilan dengan penuh kegembiraan bahkan menjadi sumber kegembiraan itu sendiri; rela berkorban dan mencintai tugasnya sebagai pewarta serta memiliki daya pikat dan daya tahan.

Roh Kudus penuntun pada kebenaran. Bagi Gereja dan para pewarta sabda teristimewa katekis, sikap yang harus dibangun dan dikembangkan adalah terusmenerus memohon bantuan dan terang Roh Kudus agar tetap tinggal dan menuntun dalam setiap karya pewartaan yang diemban oleh Gereja dan katekis. Roh Kudus akan menyatakan kebenaran tentang Allah dan pengenalan akan firman sampai kita mengenal Allah dengan benar. Usaha yang harus dikembangkan agar senantiasa dituntun Roh Kudus pada kebenaran yaitu: membaca Kitab Suci, mendekatkan diri pada Tuhan melalui doa, terus menerus mau belajar dan terbuka terhadap perubahan-perubahan yang terjadi, sikap mau bertobat, sikap dialog dengan agama lain, dan memiliki sikap mengabdi pada kebenaran.

Roh Kudus memberi petunjuk bagi perutusan katekis. Roh Kudus merupakan roh yang membimbing, memimpin dan memberi petunjuk apa yang harus dilakukan. Roh Kudus tidak akan membiarkan para pewarta sabda Allah bekerja tanpa ada tujuan yang jelas dan pasti. Petunjuk yang diberikan Roh Kudus pada katekis akan semakin jelas apabila katekis dalam hidupnya mengusahakan sikap: pertama, rajin membaca Kitab suci dan menjadikan kitab Suci sebagai sumber inspirasi dari karya pewartaannya; kedua mendekatkan diri pada Tuhan melalui doa, baik doa secara pribadi maupun bersama dan terutama mengembangkan devosi kepada Roh Kudus; ketiga, menghadiri perayaan Ekaristi yang merupakan sumber dan puncak hidup Kristiani; keempat mengembangkan sikap cinta kepada pribadi; kelima berkumpul dalam persekutuan; dan keenam yang hendaknya dipupuk adalah sikap bermati raga. 


\section{KESIMPULAN}

Para katekis dituntut untuk terus-menerus mengembangkan diri. Pengembangan tersebut meliputi segi spiritualitas, pengetahuan dan keterampilan. Pertama, pengembangan spiritualitas dapat dengan rajin membaca Kitab Suci, berdoa baik secara pribadi maupun kelompok/bersama mohon semangat misioner dan panggilan bagi karya perutusan Gereja, rajin mengikuti perayaan Ekaristi, terus-menerus membaharui diri dengan bertobat dan mohon ampun pada Tuhan, mengembangkan devosi kepada Roh Kudus melalui doa Datanglah Roh Kudus, Mohon Tujuh Karunia Roh Kudus, dan Doa Roh Kudus. Pengembangan spiritualitas dapat juga dilakukan dengan mengikuti retret ataupun rekoleksi yang berkaitan dengan panggilannya sebagai seorang katekis, mengikuti seminar hidup dalam Roh, membiasakan diri maupun kelompok mengawali setiap kegiatan ataupun pertemuan rutin dengan berdoa mohon kehadiran Roh Kudus serta mengadakan doa Novena kepada Roh Kudus.

Kedua, pengembangan pengetahuan dari katekis bias dicapai dengan mendalami ilmu-ilmu gerejawi (Kateketik, Pastoral, Teologi, Moral, Kitab Suci, Hukum Gereja, Liturgi) dan ilmu-ilmu kemanusiaan (Sosiologi, Psikologi, Pedagogi, dan lain-lain). Usaha lain untuk mengembangkan pengetahuan juga dapat dengan terus-menerus belajar atau on going formation terhadap segala perkembangan yang terjadi misalnya dengan mengikuti kursus, seminar, diskusi, lokakarya, mengadakan penelitian, studi pribadi dan lain sebagainya.

Ketiga, keterampilan yang perlu dikembangkan oleh para katekis adalah berkomunikasi, berdialog, berefleksi, menganalisa, memahami tanda-tanda zaman dalam terang Kitab Suci, menyusun, melaksanakan dan mengevaluasi program kateketik pastoral, serta keterampilan dalam kepemimpinan dan manajemen. Pengembangan keterampilan tersebut dapat melalui kursus-kursus, seminar, lokakarya ataupun juga studi pribadi. Selain itu, harus diingat bahwa seorang katekis dituntut tetap konsekwen dan konsisten dalam menjalankan tugas perutusan dengan disertai dedikasi tinggi dan semangat siap berkorban. 


\section{DAFTAR PUSTAKA}

. 1998. Dokumen Konsili Vatikan II (terj). Jakarta: Obor. . 1999. Kitab Hukum Kanonik. Jakarta: Obor.

Adisusanto, FX. 1993. "Peranan Katekis Dalam Misi Gereja Di Indonesia” dalam Ekawarta No 6/XIII.

Komkat KWI. 1997. Pedoman untuk Katekis. Yogyakarta: Kanisius

Konferensi Waligereja Indonesia, Komisi Kateketik. 2003. Petunjuk Umum Katekese. Jakarta: Dep Dokumentasi dan Penerangan KWI.

Kotan, Daniel Boli (ed). 2005. Identitas Katekis di Tengah Arus Perubahan Jaman. Jakarta: Komisi Kateketik KWI.

Lembaga Alkitab Indonesia. 1974. Alkitab Elektronik 2.0.0 - Alkitab Terjemahan Baru. Lembaga Alkitab Indonesia: Jakarta

Mandagi, L. 1994. Identitas Pendidik Katolik: Sumbangan Dari Dokumen Gereja. Yogyakarta: Pusat Pastoral.

Martasudjita, E. 2005. Semangat Misioner. Yogyakarta: Kanisius.

Paulus II, Yohanes. 1992. Catechesi Tradendae (Penyelenggaraan Katekese). Jakarta: Dep Dokumentasi dan Penerangan KWI.

---------. 1992. Ensiklik Redemptoris Missio (Tugas Perutusan Sang Penebus). Jakarta: Dep Dokumentasi dan Penerangan KWI.

Tondowidjojo, John. 1990. Arah dan Dasar Kerasulan Awam. Yogyakarta: Kanisius.

Wijaya, Albert I Ketut Deni. 2016. “Roh Kudus Bagi Karya Katekis,”dalam Jurnal Pendidikan Agama Katolik (JPAK) Vol.16 No.8.

------. 2018. “Katekis dalam Perutusan Gereja di Tengah Tuntutan Profesional” dalam Jurnal Pendidikan Agama Katolik (JPAK) Vol. 20 No.10. 